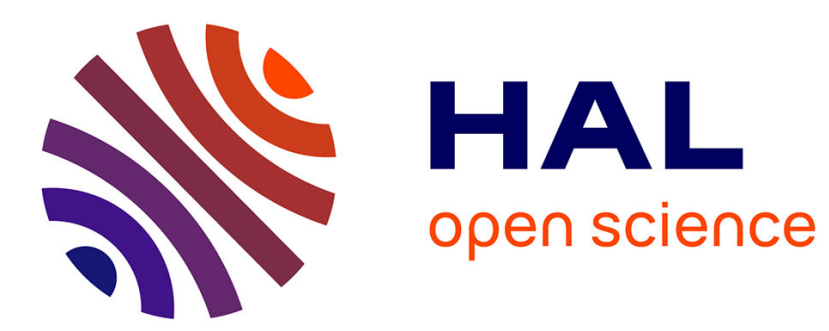

\title{
HOW MATHEMATICS TEACHERS HANDLE LESSONS IN TECHNOLOGY ENVIRONMENTS
}

\author{
Maha Abboud
}

\section{To cite this version:}

Maha Abboud. HOW MATHEMATICS TEACHERS HANDLE LESSONS IN TECHNOLOGY ENVIRONMENTS. Nordic Research on Mathematics Education, 2009. hal-02610713

\section{HAL Id: hal-02610713 \\ https://hal.science/hal-02610713}

Submitted on 17 May 2020

HAL is a multi-disciplinary open access archive for the deposit and dissemination of scientific research documents, whether they are published or not. The documents may come from teaching and research institutions in France or abroad, or from public or private research centers.
L'archive ouverte pluridisciplinaire HAL, est destinée au dépôt et à la diffusion de documents scientifiques de niveau recherche, publiés ou non, émanant des établissements d'enseignement et de recherche français ou étrangers, des laboratoires publics ou privés. 


\title{
HOW MATHEMATICS TEACHERS HANDLE LESSONS IN TECHNOLOGY ENVIRONMENTS
}

\author{
Maha ABBOUD-BLANCHARD
}

DIDIREM, Research team in the didactics of mathematics, University Paris 7, France This study investigates the practice of an 'ordinary' mathematics teacher in a technology based-lesson. The analysis of the students' tasks, the students groups' management and the discourse of the teacher provides elements that attempt to characterize teachers' actions in a technology environment. It suggests that, on a cognitive level, the teacher's activities might be considered as similar to those in a pencil-and-paper environment. As on the mediation level, it shows a phenomenon of a class split in several 'mini-classes' that function autonomously and to which the teacher must adjust regularly, repeating the same discourse to each of them. These findings, and others presented in the article, demonstrate on a wider scale how the coherent system of a well-established practice is disturbed by the use of an ICT environment.

\section{INTRODUCTION}

Until recently, research about mathematics teachers using technologies in their classes was not mainstream. These findings ensued particularly from an extensive survey of ICT [1] in the teaching and learning of mathematics (Lagrange et al., 2003). The survey took into account more than 600 publications (before 1999) dealing with technology. As part of the team leading this survey, my own contribution consisted in examining publications that focused on teachers' practices. I found that they are rather rare and the objective of the few existing are essentially to examine 'exemplary teacher activity' in innovative situations, or on the contrary, to highlight difficulties and constraints encountered by 'ordinary' teachers. More recent studies show that teaching with technology is a very complex issue which needs to be regarded in a holistic way in order to better understand the whole experience of using technology in the classroom (Monaghan, 2004) (Artigue et al., 2006). It also shows that teaching practices are influenced by a system of beliefs and knowledge about learning, teaching, mathematical content, pedagogical content and institutional constraints (Kendal and Stacey, 2002).

The study referred to in this paper aims to contribute to the exploration of the complexity of integrating ICT into teaching. The main issue is to characterize teacher's activity and its impact on students' achievement/learning with technology. Therefore, I present here in a third section, the analysis of the activity of a mathematics teacher in an ICT-based lesson according to three polarities in complete interaction: tasks proposed for the students' learning (cognitive pole), the management of the students' groups (pragmatic pole), the discourse and the interaction with students (relational pole). More generally, in the last section, I compare my findings to 
results on practices in non-technology based lessons and crosscheck them with previous relevant research in ICT-mathematics education.

\section{FRAMEWORK AND METHOD}

This study uses methods and concepts developed within the general framework of the two-fold approach, which operate both a didactical and an ergonomical perspective in analysing the factors that determine the teacher's activity as well as that of students prompted by the teacher in class (Robert and Rogalski, 2005). Within this framework, analyzing lessons takes into consideration the fact that there are two main types of channels used by the teacher in classroom management: the organization of tasks prescribed to students (cognitive-epistemological dimension) and the direct interactions through verbal communication (mediative-interactive dimension). Furthermore, the authors (ibid) differentiate task from activity: task is what is to be carried out; activity is what a person develops when realising the task.

In the research presented in this article, students' activities are studied bearing in mind that they depend more or less on the teacher's approach: either articulating exercises and courses or organizing work in class. First, I will report on the a priori analysis of the students' tasks and what they are supposed to undertake in terms of initiative and use of knowledge already acquired and actually needed to execute the tasks. This may be: a partial recognition of the knowledge to be used, a recognition of the modalities of this use, a use of intermediaries-notation, a change of frames or a combination of different concepts to be applied. A task is considered simple and isolated when it does not require the use of different "objects of learning" (ibid).

Secondly, I will present the lesson in progress, that is to say, what really happened in the classroom by underlining the teacher's aids and by studying the features of his/her discourse. The teacher intervenes often to provide assistance to the students sometimes modifying their activities. A. Robert (2008) defined two types of aids, depending on whether they modify the activities scheduled or if they add something to the students' action. The first, "procedural help", deals with the prescribed tasks by modifying activities with regard to those planned from the presentation of the task. It corresponds to indications that the teacher supplies to the students before or during their work. The second, "constructive help", adds something between the strict activity of the student and the (expected) construction of the knowledge that could result from this activity. These interventions prompt students to somewhat put what they have realised into perspective. The analysis of the teacher's discourse provides more information about how he/she contributes to model students' activities. This analysis has been undertaken using a methodology constructed by M. Paries (2004) who adapted tools used in psychology, notably the functions of scaffolding defined by J. Bruner (1983) who regarded interaction as the major form of assistance provided by adults for cognitive development. Thus, she studied the role of discourse in the mediation of cognitive development and defined functions of the mathematics teacher's discourse 
by specifying the manner in which he/she intervenes gradually in detail in the students' work. M. Paries distinguishes two groups of functions:

- The "cognitive functions" linked to the task to realise and to the mathematical content. These functions are: distribution of tasks, introduction of a sub-task, assessment, justification and structuring.

- The "functions of enrolment" apparently independent from the task, at least in their formulation, but can have an impact on its realisation. They allow the teacher to maintain communication. These functions are: engagement, mobilization of the student's attention, encouragement and mutualisation.

\section{THE STUDY}

The lesson studied here is about space geometry in a class of the fourth year of secondary education. It takes place in the computer room with the use of a dynamic geometry software: GeospacW; students are assigned by groups of two or three to a computer. The topic is the section of a pyramid by a plane parallel to the basis. Students have already solved the first and second parts of the problem in a previous session. The lesson in progress is about solving the third part of the problem. The teacher, Anna, seems to have an episodic use of technology tools with her students, which I would not qualify as significant use.

\section{Brief analysis of the tasks}

In the beginning, students have to download the file containing the figure and constructions achieved in the previous session. It is a given cube ABCDEFGH in which they have drawn: I, middle of $[\mathrm{EF}]$ and J, middle of $[\mathrm{AB}]$. They have explored the figure by doing rotations, and have proved that: triangle JCD is isosceles and triangle IJD is rectangle. They have also found the lengths of JC and JD and the volume of IJCD. In the observed lesson they have to give answers to the questions of the third part of the problem. A worksheet is provided.

First, students have to draw the section of the pyramid IJCD by a plane passing by M, the middle of $[\mathrm{IJ}]$, and parallel to the basis JCD, getting thus two points $\mathrm{N}$ (middle of [IC]) and Q (middle of [ID]). This technological-task (t-task) is entirely guided by a set of manipulation commands and students only need to follow the instructions. Second, they have to examine, with GeospacW commands, the triangles JCD and MNQ. The aim here is that student gets to see MNQ as the $1 / 2$ reduction of JCD. Once done, tasks that follow are mathematical-tasks (m-tasks): to calculate the areas of triangles MNQ and JCD, to calculate the volume of IMNQ and to compare it with the volume of IJCD. These m-tasks are complex and require a certain number of adjustments:

- taking initiatives (for example, to construct the height in a triangle in order to calculate its area); 
- making the necessary adaptations to apply formulas of areas or volumes in the particular case of this exercise;

- operating a change of frames (when comparing the two volumes) that consists in introducing the comparison of two numbers in a geometric frame.

The t-tasks are thus located only in the beginning of this part of the problem; all the questions that follow imply m-tasks. There are four t-tasks: downloading the figure; creating M; creating the section MNQ; examining successively MNQ and JCD. These t-tasks are simple. The first two are familiar and have been dealt with in the previous lesson. The teacher has facilitated the third one; students have only to execute a set of instructions. The last one requires, on a technological level, to recognise the set of GeospacW commands needed to isolate a plane (JCD and MNQ) and, on a mathematical level, to identify that MNQ is the $1 / 2$ reduction of JCD. Therefore, $t-$ tasks are designed to be simple, guided and quickly executed in order to get a stronger focus from the students on m-tasks. The latter are more complex and require time to be carried out.

\section{The development of the lesson and the students' activities: some indications}

Globally, I have noticed that students are often in autonomy-mode and for very long moments. When she is present, Anna divides the task into sub-tasks to be immediately executed by students, in a bid to get them to pursue their work quickly. Her interactions with the groups, at different stages of the process, are much the same as we will see when we examine her discourse. The teacher's collective interactions are rare. In the beginning of the lesson, she exposes the work to be done, and at the end, the work to be finished. Half-hour after the beginning of the lesson, she points out to all the class the link between some questions and some theorems seen previously in class and at another moment she mentions the time left.

Students' activities differ from one group to another. All the groups created the section of the pyramid and examined planes JCD and MNQ but few reached the calculation of the length of $\mathrm{MN}$, which was the object of the first question. No one reached the comparison of the pyramids' volumes (last question).

Two profiles of students' groups can be noticed: students who couldn't work without the tutorship of the teacher as for one group that did not even, after 38 minutes, manage to draw the section of the pyramid; or students who went on with the assignment more or less autonomously.

\section{The teacher's help}

The assistance of the teacher consisted almost exclusively in procedural help; it helped simplify the students' activities. Indeed, here dividing the tasks into simple sub-tasks is clear: sometimes Anna nearly dictates the work to do and times she even takes herself the mouse to accomplish some sub-tasks. Often, when the teacher is interacting with a group, students only follow her instructions, or even finish a sentence that she 
begun. I might here underline that the teacher can stay with every group a very short time and thus her assistance allows students to pursue their work on their own. One can wonder if dividing the task is some how a way for Anna to be efficient. Still, Anna did not succeed to meet her objective; students were too slow in the construction of the section of the pyramid. She had prepared simple t-tasks in order to help the students to start quickly the mathematical activity. Perceiving during the lesson that these tasks took more of time than expected, she tried to accelerate their execution by doing the work herself or by coaching students step by step in the execution.

The help of Anna focused nearly exclusively on the construction of the section of the pyramid, even though this t-task only required the meticulous execution of a set of GeospacW commands provided in the worksheet. These aids cannot be qualified as procedural help, since there is not modification/simplification of the scheduled activities. This type of assistance is not characterized in the typology, defined by Robert (ibid.) used in this study. This brings me to the introduction, in this context, of a new type of help that I call 'manipulatal help' which consists in accompanying the student so that the planned activity is achieved without modification of the task, because the latter is already sufficiently reduced and needs no more dividing. This type of help is directly dependent on the use of instruments. It is rather present in technology-based lessons, given the ubiquity of the instrument, but it also can be found in a non-technology environment when an instrument is used for the first time.

\section{The functions of discourse}

I will not detail here the study of the teacher's discourse, because of the restricted length of this paper. I will rather give some significant percentages of the functions of discourse. First, I observe that the functions of enrolment have a low percentage (7\%) which might be explained by the fact that the mobilization of the students' attention and the engagement in tasks is supported by the technology-environment itself. I notice also that structuring accounts for an important rate among cognitive functions $(28 \%)$. As stated above, Anna is aware of the slow execution of the tasks and tries, by this means, to accelerate the pace. As for the cognitive function of the introduction of sub-tasks, the high percentage $(21 \%)$ is coherent with the analysis of the m-tasks. These tasks are complex, need adjustments, and on top of that, students' work progresses slowly. The function of mutualisation stands at only $15 \%$ of the total and corresponds to interactions with groups of students and not to collective interactions. Actually, after the start (collective phase), the class splits into several 'mini-classes' (groups of two or three students per computer) which function separately and to which the teacher talks independently from the remainder of the class. Besides, certain functions of the discourse apparently succeeded in these 'mini-classes' in this same order: assessment, structuring, introduction of a sub-task. Thus, the succession of the teacher's intervention in every 'mini-class' might be described as following:

- She arrives in a mini-class; 
- She assesses the work already done;

- She tutors the students in their solving activity by structuring and introducing subtasks;

- When students execute these tasks correctly, she moves on to another mini-class.

\section{CONCLUSIONS AND DISCUSSION}

In this section, I will synthesise my findings and on the one hand, try to compare it with the results of a similar analysis of a non-technology-based lesson at the same class level and about the same problem solving [2] (Abboud-Blanchard, Paries, 2008) in order to highlight what actually is characteristic of an ICT-based lesson. On the other hand, I will illustrate continuities between these findings and those of some studies reviewed above, to suggest that a number of results may be more widely transferable.

The initial global project of Anna, in ICT environment, seems to be similar to the one that would be led in pencil-and-paper environment; the same exercise has to be solved by all the students. This exercise deals with the resolution of mathematics tasks identical to those that could be proposed in a pencil-and-paper environment. This result is close to what Kendal and Stacey (2002) underline, about CAS [3], that the mathematical knowledge and skills stay globally within the range of those expected in non-technological environment.

However, work in computer room generally entails that students be in groups of two or three per machine. Consequently, there is a class split in several 'mini-classes' working relatively independently, and a quasi disappearance of collective phases except the collective time management. The teacher is not able, in certain cases, to generalize the supply of certain indications given only to some students whereas they could be useful to all the others. M. Artigue et al. (2006) encountered the same features notably the fact that individual interactions substitute for collective interactions and that institutionalisation phases are nonexistent because of the different 'trajectories' of students.

Besides, for each of these mini-classes, the teacher adapted to what students were doing and to their reasoning of the moment, whereas in pencil-and-paper lessons, it is more often students who adjust themselves to the teacher's project. This appears to be an important element of the management of a technology-based lesson which differentiates it from a non-technology one. Moreover, the analysis of the interactions showed similarities in the successions of the functions of the discourse among the mini-classes which brought me to an ordered description of Anna's activities (see above) when she speaks to a group of students working on a machine

This global difference is also mentioned by Monaghan who adds that the teacher talk is generally directed to all students around a computer, which can be interrelated with 
the fact that technology is often not just a tool to do mathematics but is also "a medium for expressing the mathematics" (Monaghan, 2004)

The functions of enrolment are present in the discourse; they seem to be taken in charge by the software. Generally, interactions with the computer help students to become more autonomous (see Artigue et al., 2006). There is a clear majority of cognitive functions that operate as help; procedural help. This type of support is partly motivated by the teacher's concern about the progress of the students' work, his/her purpose being to have the whole exercise done. Actually, the division of tasks into sub-tasks is efficiency-driven. Some of these become therefore only a mechanical execution of a set of assignments and this, on a methodological level, initiated my introduction of a new type of aids: 'manipulatal' help.

As for students' activities, the use of the software seems to entails some very important discrepancies among students. Indeed, the students' activities differ from one group to another: ranging from a simple execution of sub-tasks to the development and follow-up of a solving strategy. For some of the groups, the activities are made even more interesting as the students are autonomous. For others, the use of the software is difficult so that it takes them some time before they get down to do the mathematical task.

Finally, the activity of the teacher in an ICT environment does not seem to be efficient in terms of time and effort compared to the same activity in a pencil-and-paper environment. Indeed, the teacher has, on the cognitive level, a practically similar activity as in a non-technology environment. This can be traced to some indications provided by Ruthven and Hennessy (2002) about teachers who initially view technology through the lens of their established practice, and employ it accordingly. Nevertheless, this activity becomes time-and-effort consuming because of its redundancy; the teacher having each time to adapt himself/herself to every mini-class he/she is tutoring. The return to collective phases to unify knowledge of students is all the more difficult as students have disparate paces. This observation may contribute to explain the feeling of "unfinished mission" which teachers often have after a lesson in a computer room. Other difficulties seem to be related to specificities of the environment and enhance the previous difficulties. Indeed, not all the students handle the software with ease, thus the teacher has to provide help which is not common in a mathematics course. He/she has also to 'share' with the computer certain functions of enrolment, which disturbs the usual management of the class.

These various elements could contribute to understand the persistently hesitation of many teachers to integrate ICT into their teaching. 


\section{ACKNOWLEDGEMENTS}

This paper is initiated by a study conducted in collaboration with M. Paries who used the framework developed in her PhD work, under my supervision, to analyze some of the data in this study. I would like here to thank her.

\section{NOTES}

1. ICT: Information and Communication Technologies

2. The length restriction on this paper prevents a full presentation of the data and analysis of this lesson.

3. CAS: Computer Algebra Systems

\section{REFERENCES}

Abboud-Blanchard, M., Paries, M.: 2008 'Etude de l'activité de l'enseignant dans une séance de géométrie dynamique au collège', in Vandebrouck (ed.) La classe de mathématiques: activités des élèves et pratiques des enseignants, Ed. Octarès, Toulouse.

Artigue, M. (dir), Abboud-Blanchard, M., Cazes, C., Vandebrouck, F.: 2006 Suivi de l'expérimentation de la région Ile de France : ressources en ligne pour l'enseignement des mathématiques en classe de seconde, Rapport final, IREM de Paris 7.

Bruner, J.: 1983 Le développement de l'enfant: savoir faire, savoir dire. Presses Universitaires de France, Paris.

Kendal M., Stacey K.: 2002 'Teachers in transition: Moving towards CSA-supported classrooms', ZDM 34(5), 196-203.

Lagrange J.B., Artigue M., Laborde C., and Trouche L.: 2003 'Technology and mathematics education: a multidimensional study of the evolution of research and innovation', in A.J. Bishop , M.A. Clements, C. Keitel, J. Kilpatrick and F.K.S Leung (eds.) Second International Handbook of Mathematics Education, 239-271.

Monaghan, J.: 2004 'Teachers' activities in technology-based mathematics lessons', International Journal of Computers for Mathematical Learning 9, 327-357.

Paries M.: 2004, Comparaison de pratiques d'enseignants de mathématiquesRelations entre discours des professeurs et activités potentielles des élèves, Recherches en didactique des mathématiques, 24, (2.3).

Robert, A., Rogalski, J.: 2005 'A cross analysis of the mathematics teacher's activity. An example in a French $10^{\text {th }}$ grade class', Educational Studies in Mathematics 59, 269-298. 
Robert, A.: 2008 'Contributions dans la partie 0, partie 1 et conclusion', in Vandebrouck (ed.) La classe de mathématiques : activités des élèves et pratiques des enseignants, Ed. Octarès, Toulouse.

Ruthven, K., Hennessy, S.: 2002 'A practitioner model of the use of computer-based tools and resources to support mathematics teaching and learning class', Educational Studies in Mathematics 49, 47-88. 